\title{
Rad53-dependent phosphorylation of Swi6 and down-regulation of C LN 1 and C LN 2 transcription occur in response to DNA damage in Saccharomyces cerevisiae
}

\author{
Julia M. Sidorova and Linda L. Breeden ${ }^{1}$ \\ Fred Hutchinson Cancer Research Center (FHCRC), Basic Sciences Division, Seattle, Washington 98109-1024 USA
}

Budding yeast possesses a checkpoint-dependent mechanism of delaying $G_{1}$ progression in response to $U V$ and ionizing radiation DNA damage. We have shown that after a pulse of DNA damage in $G_{1}$ with the alkylating agent MMS, there is also a MEC 1-, RAD 53-, and RA D 9-dependent delay in $G_{1}$. This delay occurs at or before Start, as the MMS-treated cells do not bud, remain sensitive to $\alpha$-factor, and have low C LN 1 and C LN 2 transcript levels for a longer time than untreated cells. We further show that MMS directly and reversibly down-regulates CLN 1 and CLN 2 transcript levels. The initial drop in C LN transcript levels in MMS is not RAD 53 dependent, but the kinetics of reaccumulation of CLN messages as cells recover from the damage is faster in rad53-11 cells than in wild type cells. This is not an indirect effect of faster progression through $G_{1}$, because C LN transcripts reaccumulate faster in rad53-11 mutants arrested in $G_{1}$ as well. In addition, the recovery of CLN mRNA levels can be also hastened by a SWI6 deletion or by overexpression of the truncated Swi4 (Swi4-t) that lacks the carboxy-terminal domain through which Swi4 associates with Swi6. This indicates that both Rad53 and Swi6 are negative regulators of CLN expression after DNA damage. Finally, Swi6 undergoes an MMS-inducible, RA D 53-dependent phosphorylation in $\mathbf{G}_{1}$ cells, and Rad53, immunoprecipitated from MMS-treated cells, phosphorylates Swi6 in vitro. On the basis of these observations, we suggest that the Rad53-dependent phosphorylation of Swi6 may delay the transition to S phase by inhibiting C LN transcription.

[Key Words: MMS; CLN1; CLN2; RAD53; SWI6; cell cycle; checkpoint]

Received March 7, 1997; revised version accepted September 12, 1997.

DN A damage checkpoints ensure that a cell with lesions in its DNA does not divide before the damage is eradicated. In the yeast Saccharomyces cerevisiae, three DNA damage-inducible checkpoints have been identified that operate in $\mathrm{G}_{1}, \mathrm{~S}$, and $\mathrm{G}_{2}$ phases of the cell cycle (Weinert and Hartwell 1989; Siede et al. 1993, 1994; Weinert et al. 1994; Paulovich and Hartwell 1995; Paulovich et al. 1997a). Two genes, MEC1/ESR1/SAD3 and RAD53/MEC2/SPK1/SAD1, appear important for the performance of all three checkpoints (Allen et al. 1994; Weinert et al. 1994; Paulovich and Hartwell 1995; Siede et al. 1996). In addition, RAD9, RAD17, RAD24, and MEC 3 are involved in $\mathrm{G}_{1}$ and $\mathrm{G}_{2}$ checkpoints (Siede et al . 1993, 1994; Weinert et al. 1994). These checkpoint gene products delay the cell cycle when DN A damage is present, which allows time for repair and improves survival

${ }^{1}$ Corresponding author.

E-MAIL Ibreeden@fhcrc.org FAX (206) 667-6526. in the presence of damaging agents. MEC1 encodes a member of a PI kinase family and has homologs in fission yeast, Drosophila, mice, and humans (Al-Khodairy and Carr 1992; Hari et al. 1995; Morrow et al. 1995; Savitsky et al. 1995; Pecker et al. 1996). The kinase activity of $\mathrm{Mecl}$ has not been demonstrated, al though it is thought that $M$ ecl, its close yeast homolog Tel 1 , and similar kinases, like ATM of humans, are protein, rather than li pid, kinases (Hunter 1995). RAD53 encodes a dual specificity kinase, whose catalytic activity has been demonstrated, but its substrate specificity remains unidentified (Zheng et al. 1993; Sun et al. 1996).

Rad9, Rad17, Rad24, and Mec3 are thought to be involved in recognition of damage and initiating a signal transduction cascade that activates M ecl and Rad53 (Lydall and Weinert 1995; N avas et al. 1996; Sanchez et al. 1996; Sun et al . 1996). In turn, Mecl and Rad53 transmit the signal to critical targets including cell cycle machinery and DNA repair enzymes. Two biochemical events have been detected upon DNA damage in cells. First, 
Rad53 undergoes phosphorylation that is dependent on M ec1, Rad9, Rad17, Rad24, and M ec3 ( $N$ avas et al. 1996; Sanchez et al. 1996; Sun et al. 1996). Second, there is an induction of transcription of a large group of genes that are involved in DN A replication and repair (A boussekhra et al. 1996; Kiser and Weinert 1996; N avas et al. 1996). However, not much is known with regard to the mechanisms of the $G_{1}, S$, or $G_{2}$ cell cycle arrests in response to the DN A damage.

Recently it has been shown that yeast cells irradiated by $U V$ or $X$ rays in early $G_{1}$ can delay the onset of Start in a checkpoint-dependent manner (Siede et al. 1993, 1994). Start, in this context, is operationally defined as the point at which cells have committed to the mitotic cell cycle and are resistant to arrest by $\alpha$-factor. This commitment process involves accumulation of threshold levels of $G_{1}$ cyclin proteins, $C \ln 1$ and $C I n 2$, which in turn triggers destruction of B-type cyclin inhibitor Sic1 and thereby irreversibly commits cells to S phase and mitosis (for review, see Cross 1995; King et al. 1996; $\mathrm{N}$ asmyth 1996). The rate of $\mathrm{CIn} 1$ and $\mathrm{CIn} 2$ accumulation is regulated primarily at the transcript level, which can vary depending on growth conditions and affect the length of the $\mathrm{G}_{1}$ phase (Baroni et al. 1994; Tokiwa et al . 1994; Willems et al. 1996).

In this work we show that MMS, a DNA-damaging agent, can induce a Mec1-, Rad53-, and Rad9-dependent delay before Start that is similar to the one observed by Si ede and coworkers after UV or X-ray irradiation (Siede et al. 1993, 1994). The M M S-induced del ay is characterized by a prolonged inhibition of CLN 1 and CLN 2 transcription, followed by a gradual reaccumulation of these transcripts and resumption of the cell cycle. The reaccumulation of CLN mRNA is faster in a rad53-11 checkpoint mutant and in a swi 6 mutant strain than in the wild type. This is not an indi rect consequence of the fact that these mutants progress through $\mathrm{G}_{1}$ faster, because it can also be observed in $\mathrm{G}_{1}$-arrested cells. Overproduction of a truncated form of Swi4, which activates CLN 1 and CLN 2 transcription but is independent of Swi 6 in its activity, can also reduce the del ay of S phase upon M M S treatment. This suggests the possibility that Rad53 might act on Swi6 to inhibit CLN transcription in damaged $G_{1}$ cells. We have found that Swi6 undergoes a Rad53-dependent phosphorylation that is induced in the presence of MMS in vivo. The kinase responsible is likely to be Rad53 or an associated kinase because Swi 6 can be phosphorylated by immunoprecipitated Rad53 in vitro in a pattern resembling the damage-induced pattern in vivo. On the basis of these observations, we suggest that reduced transcription of CLN 1 and CLN2 owing to an inhibitory phosphorylation of Swi 6 contributes to the checkpoint-mediated delay of Start.

\section{Results}

MMS damage in early $G_{1}$ delays the onset of CLN transcription

MMS is a DNA-alkylating agent that methylates bases and can induce a variety of lesions including strand breaks (Dhillon and Hoekstra 1994). We have used this agent to study the $G_{1}$ checkpoint that delays the onset of $S$ phase in the presence of DNA lesions. Figure 1 shows the behavior of wild-type cells that were arrested in early $\mathrm{G}_{1}$ by $\alpha$-factor, treated or not treated with $0.1 \% \mathrm{M} \mathrm{MS}$ for $30 \mathrm{~min}$, and then allowed to progress through the cell cycle by removal of MMS and $\alpha$-factor. Samples were taken to determine budding index and DN A content. As can be seen from Figure $1 A$, the MMS-treated cells remain unbudded for at least $45 \mathrm{~min}$, whereas the untreated cells bud between 15 and $30 \mathrm{~min}$ after release from the $\alpha$-factor. FACS profiles of these cultures are consistent with the budding indexes and show (Fig. 1B) that the MMS-treated cells maintain a $1 \mathrm{~N}$ DNA content and do not enter S phase for $\sim 45 \mathrm{~min}$. In contrast, the untreated cells are al ready well into $S$ phase 30 min after the rel ease from $\alpha$-factor. In addition to the slow entry into S phase, a consi derable fraction of the M M S-treated cells are still in S phase 105 min after rel ease. This very slow S phase is consistent with previous observations that M MS can induce the S-phase checkpoint (Paulovich and Hartwell 1995).

UV irradiation in early $G_{1}$ can transiently arrest cells before Start (Siede et al. 1993, 1994), as judged by the fact that the arrested cells are sensitive to $\alpha$-factor. Cells arrested in $G_{1}$ by MMS treatment are also $\alpha$-factor sensitive (see below). Moreover, this pre-Start arrest is reflected in CLN transcript levels. As seen in Figure 1, C and $D$, whereas untreated cells rapidly induce a normal burst of CLN 1 transcript $10 \mathrm{~min}$ after the $\alpha$-factor release, MMS-treated cells are greatly delayed in their accumulation of CLN 1 transcript. Two simple possibilities could account for this. First, MMS treatment could inhibit some early event and prevent progression to the time at which CLN transcription commences. Alternatively, MMS could directly inhibit CLN transcription, and that could be responsible for delaying Start.

\section{CLN 1 and CLN 2 transcripts are reversibly down-regulated upon $M M S$ treatment in $G_{1}$}

To address in more detail whether CLN 1 and CLN 2 transcripts are directly affected by MMS addition, wild-type yeast cultures were arrested in $\mathrm{G}_{1}$ with $\alpha$-factor and re leased into fresh media containing increasing doses of MMS. These cells were incubated for $20 \mathrm{~min}$ and harvested, and then CLN 1 and CLN 2 transcript levels were measured. We found that the CLN transcripts were spe cifically down-regulated in response to $\mathrm{MMS}$ addition in a dose-dependent manner (data not shown). To see if cell cycle progression is required to see this down-regul ation, we used a cdc4 strain, which arrests at the $G_{1} / S$ transition upon incubation at nonpermissive temperature $\left(37^{\circ} \mathrm{C}\right)$. This strain was first incubated at $37^{\circ} \mathrm{C}$ for $3 \mathrm{hr}$ to establish a uniform arrest. Then MMS was added for 30 min to an aliquot of these arrested cells, and samples were harvested for mRN A measurements. CLN 1 levels were reduced in the M MS-treated cells by 5- to 10-fold compared with untreated controls (Fig. 2, lanes 1,2). The same result was obtai ned with cdc28 cells arrested in $\mathrm{G}_{1}$ 
A

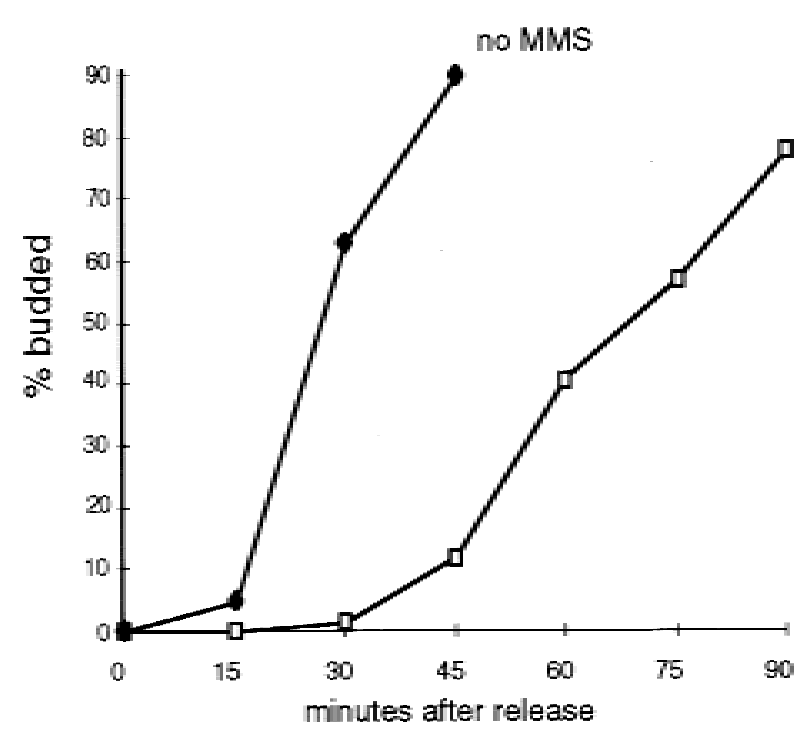

B

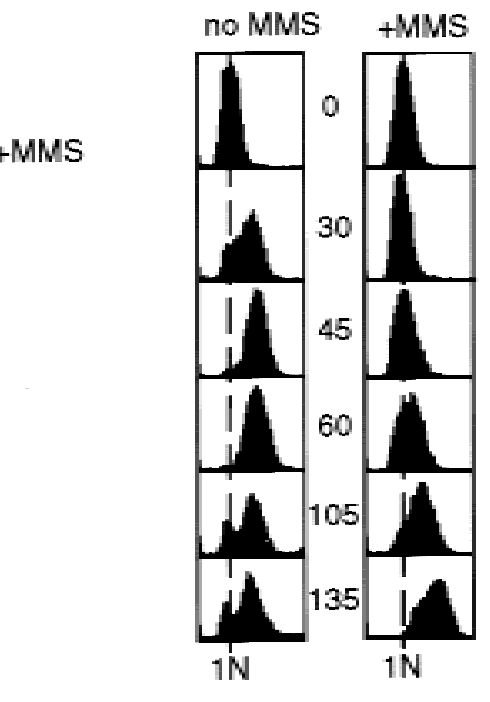

c

$\begin{array}{llllllllll}0 & 10 & 20 & 30 & 45 & 60 & 75 & 90 & 105 & 120\end{array}$

+MMS

D

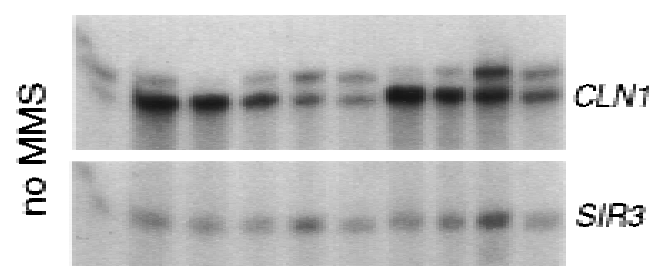

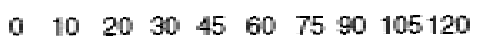
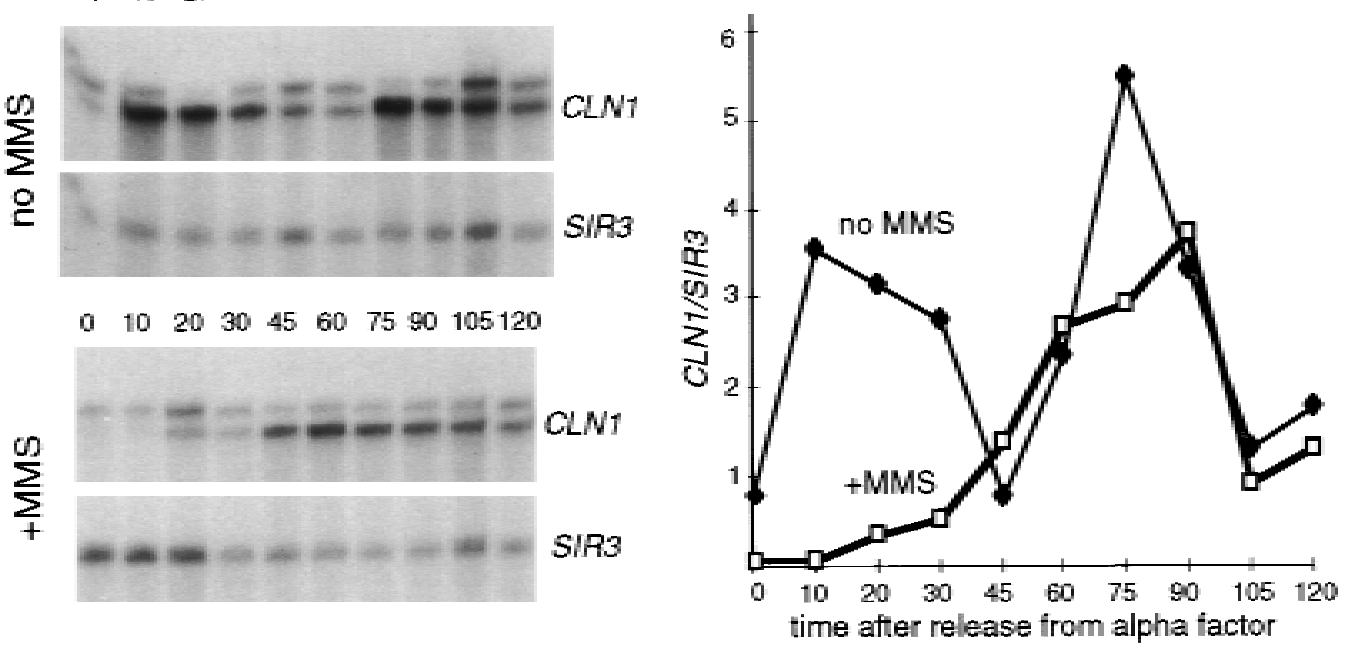

Figure 1. Exposure of $\mathrm{G}_{1}$ cells to $M M S$ causes a delay of $S$ phase. Wild-type (BY 2235) cells were arrested by $\alpha$-factor in $G_{1}$, and one-half of the culture was incubated with $0.1 \%$ M M S for $30 \mathrm{~min}$. Then M M S was inactivated as described in M aterials and M ethods, and both cultures were filtered out of $\alpha$-factor, resuspended in the fresh media, and allowed to progress into the cell cycle. These cells are $25 \%-50 \%$ viable after such treatment (data not shown). Aliquots of cultures were taken before the rel ease (time point 0 ) and every 15 min after to determine the percentage of budded cells (A) and DNA content (B). For the latter, samples were fixed, stained with propidium iodide as described in Materials and Methods, and subjected to FACS analysis. (C) A separate culture was treated as described for A and B, and aliquots for RN A isolation were taken before the release from $\alpha$-factor and every 10-15 min after. These RN As were analyzed by S1 protection with radiol abel ed probes against CLN 1 and SI R3 RN As. The protected fragments corresponding to these RN As are marked. (D) The S1 protection data presented in C were quantitated using Phosphorlmager software. CLN 1 mRN A levels were normalized to the internal control mRNA (SIR3) levels and plotted.

(data not shown). This indicates that MMS treatment significantly inhibits CLN transcription or decreases mRN A stability. We then followed CLN transcript levels for $2 \mathrm{hr}$ after MMS was removed and found that these transcripts remain low for up to $60 \mathrm{~min}$, after which they start to reaccumulate (Fig. 2B). Therefore, down-regulation of CLN transcription by MMS is prolonged but re- versible and can occur independently of cell cycle progression.

Importantly, other cell cycle-dependent transcripts that peak during $\mathrm{G}_{1}$ phase did not show the same response to M MS addition that was observed for CLN 1 and CLN2. For example, the CDC9 transcript, which is known to be DNA damage-inducible (McClanahan and 

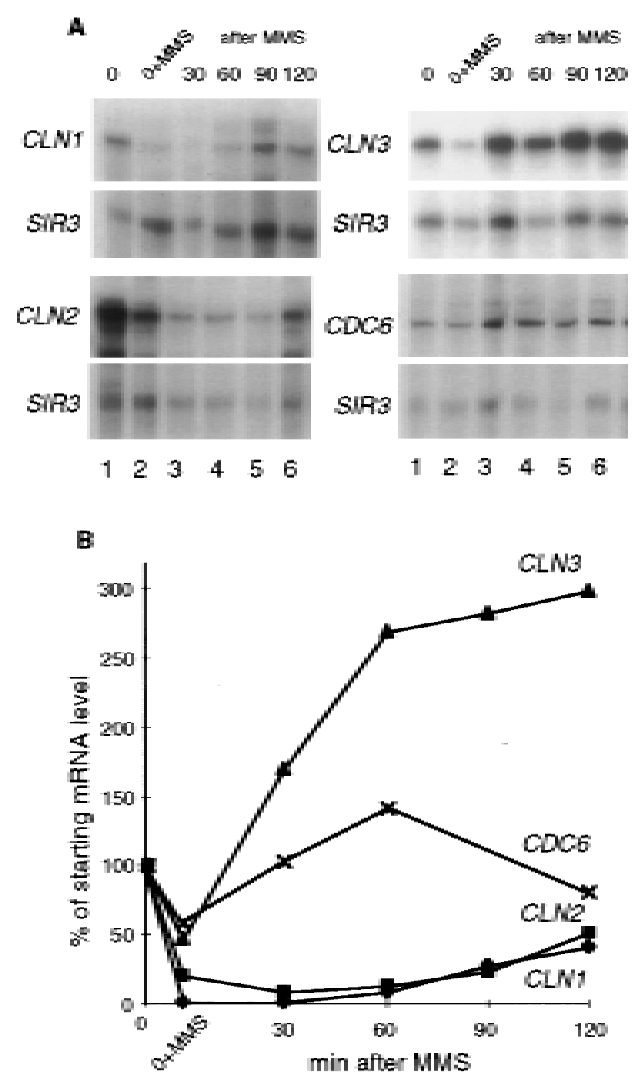

Figure 2. MMS causes reversible down-regulation of CLN1 and CLN 2 mRN As. (A) The cdc4-1 (BY 665) strain was arrested as described above and divided in two cultures, and $0.1 \% \mathrm{MMS}$ was added to one part for $30 \mathrm{~min}$, whereas the other part was incubated without MMS for $30 \mathrm{~min}$ and harvested (0). An aliquot was harvested out of the MMS-containing culture $(0+\mathrm{MMS})$, and in the rest of the culture, M MS was inactivated and the culture was filtered into the fresh $37^{\circ} \mathrm{C}$ media and allowed to recover from M MS at this temperature. Aliquots were taken throughout the time of recovery $(30,60,90$, and $120 \mathrm{~min}$ after the release from MMS). CLN 1, CLN2, CLN3, CDC6, and SIR3 mRNA levels were measured by $\mathrm{S} 1$ protection in these aliquots. (B) mRNA levels shown in A were quantitated, normalized, and plotted. The mRN A levels seen in M MS and after MMS removal are expressed as the percentage of the starting normalized mRN A level seen at $37^{\circ} \mathrm{C}$ in the untreated culture $\mathrm{N}$ ote that the 90 -min time point for CDC 6 mRN A could not be reliably normalized to its internal control, because the latter was apparently lost from this sample on the gel.

McEntee 1984; Ruby and Szostak 1985), underwent virtually no reduction in MM S and was el evated after M MS removal (data not shown). The CDC6 transcript level was reduced $\measuredangle 50 \%$ in M MS and was rapidly restored after M M S was removed (Fig. 2). The CLN 3 transcript al so dropped by $50 \%$ in the presence of MMS but was actually induced to a reproducibly higher level shortly after M M S removal. We have noted the presence of ST RE elements and three short stretches of homology to the DRE (damage response element) of RNR2 (Elledge and Davis ${ }^{1989)}$ in the CLN3 3 promoter, which could be re- sponsible for this damage-induced increase. In addition, the HIS3, MATal, and SIR3 mRN As, which were used as internal controls, displayed little or no sensitivity to MMS within the range of MMS concentrations and incubation times applied in our study. Therefore, al though high levels of MMS and/or prolonged exposure to it eventual ly eliminate all transcripts (data not shown), the CLN 1 and CLN2 transcripts are consistently more sensitive to it than the other transcripts we have monitored.

Start delay in MMS-treated cells can be reduced by deregulation of CLN transcription

The experiments shown so far suggest that CLN transcript levels may be directly affected by M MS treatment. To see whether this down-regulation of CLN levels is sufficient to explain the observed delay of $\mathrm{S}$ phase in damaged cells, we asked whether modest increases in CLN expression could shorten the delay. To do this, we first tried a strain producing elevated levels of the Swi4 transcription factor, which is a primary activator of CLN1 and CLN2 transcription (for review, see Breeden 1996). We found that simply overproducing Swi 4 from the GAL promoter does not noticeably reduce the $G_{1}$ delay after MMS as compared with the wild-type strain (data not shown). However, GAL induction of carboxyterminal ly truncated Swi4 (GAL::SWI4-t) can reduce the delay of S phase after M MS treatment. The Swi4-t strain deregulates CLN transcription such that CLN 1 message is easily detectable in $\mathrm{G}_{1}$ cells treated with MMS, and then it increases modestly during the recovery period to a peak level that is about twofold higher than that of the wild-type cells (Fig. 3A). Consistent with the deregulated CLN 1 levels, Swi4-t cells bud and become $\alpha$-factor resistant more rapidly than wild-type cells after MMS treatment (Fig. 3B,C). Thus, it appears that increased CLN levels allow a partial bypass of the MM S-induced delay of Start. This is not particularly surprising in view of the observed reduction of the CLN transcripts in response to M MS (Fig. 1), but it argues against an alternative model, which is that the $G_{1}$ delay mechanism in response to DNA damage operates exclusively via CDK inhibition.

Check point mutants have a shorter $\mathrm{G}_{1}$ delay after MMS treatment than wild-type cells

Mutations in MEC 1, RAD53, and RAD9 make cells defective in $G_{1}$ delay upon $U V$ and ionizing radiation damage (Siede et al. 1993, 1994, 1996), and they are sensitive to MMS (Paulovich and Hartwell 1995; Paulovich et al. 1997a). These mutants are also defective in their $G_{1}$ delay after M M S treatment. Figure 4 shows the kinetics of budding and DNA synthesis in isogenic wild type, rad9s, rad53-11, and mec1-1 checkpoint-defective mutants. In the absence of damage, these mutants and the wild-type cells have a si milar rate of progressi on through the $\mathrm{G}_{1} / \mathrm{S}$ transition (Fig. $4 \mathrm{~A}$ ). By 30 min after release, all three of the untreated strains have budded and entered $S$ phase. However, after treatment with a pulse of MMS damage, (Fig. 4A,B), the wild-type cells delay entry into $S$ 
A

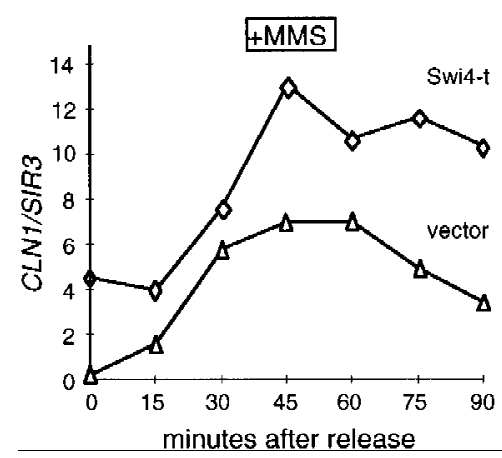

B

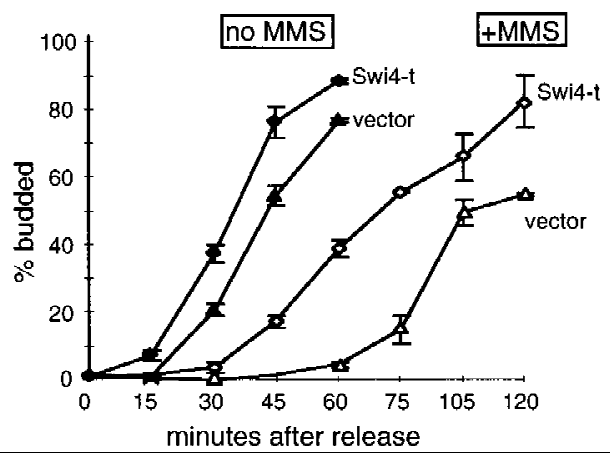

C

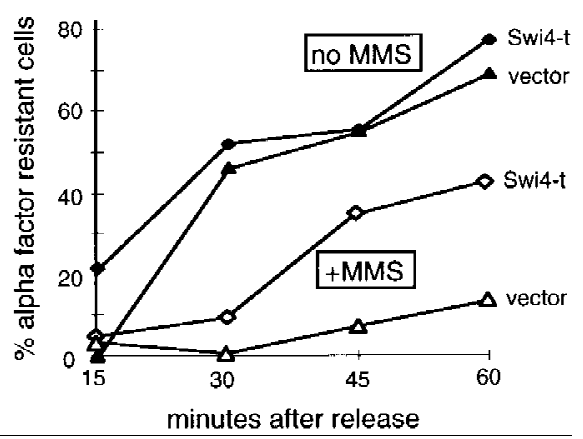

Figure 3. Overproduction of the carboxy-terminally truncated Swi4, Swi4-t, diminishes the M MS sensitivity of CLN 1 mRNA and shortens the del ay of budding and of the S-phase entry after M MS treatment. (A) The wild-type W303-1a strains transformed with the vector (pBD 860) or with the GAL::SWI4-t plasmid (pBD1168) were arrested by $\alpha$-factor in rich media with raffinose. Galactose was added to induce Swi4-t overexpression $1 \mathrm{hr}$ before the release, and in $30 \mathrm{~min} 0.1 \%$ M MS was added. After an additional $30 \mathrm{~min}$, cells were rel eased both from M M S and $\alpha$-factor and al lowed to grow in rich media with gal actose. Aliquots were collected before the rel ease and in 15-min intervals after it to perform S1 protection measurements of CLN1 and SIR3 RNA levels. These levels were then quantitated, and CLN 1 was normalized to SIR3 and plotted. (B) The same two strains were arrested by $\alpha$-factor as before, and a half of the culture of each strain was treated with $0.1 \% \mathrm{MMS}$ for $30 \mathrm{~min}$ before the release from $\alpha$-factor arrest. Aliquots were taken to count the percentage of budded cells. $\mathrm{N}$ ote that the budding results shown in $\mathrm{B}$ are the average of two independent experiments. (C) The wild-type W303-1a strain with vector (pBD860) or with the GAL::SWI4-t plasmid (pBD1168) were arrested and treated with M MS as described in B. After the release from $\alpha$-factor al one or MMS and $\alpha$-factor, the cultures were allowed to grow in rich media with galactose and aliquots were removed and placed into microtiter plate wells. To these aliquots, $\alpha$-factor (at $10 \mu \mathrm{g} / \mathrm{ml}) \mathrm{was}$ added. $\alpha$-Factor samples were incubated for 30-45 min, then formal dehyde was added to $4 \%$ to fix the cells, and the percentage of budded cells was counted.

phase and are still primarily in $\mathrm{G}_{1}$ as judged by budding (Fig. 4A) and FACS analysis (Fig. 4B) at the 150-min time point, whereas the rad9s, rad53-11, and mec1-1 strains go through this transition $\sim 30$ min faster. The checkpoint-defective strains also go through Start earlier than wild type, as judged by $\alpha$-factor resistance (Fig. 4C). In-

A

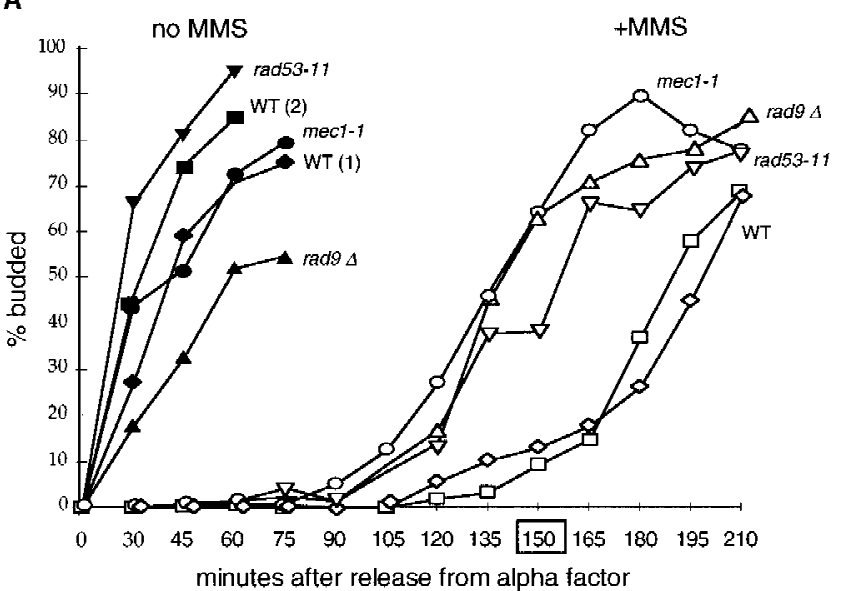

B

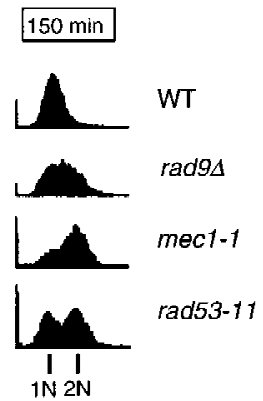

c

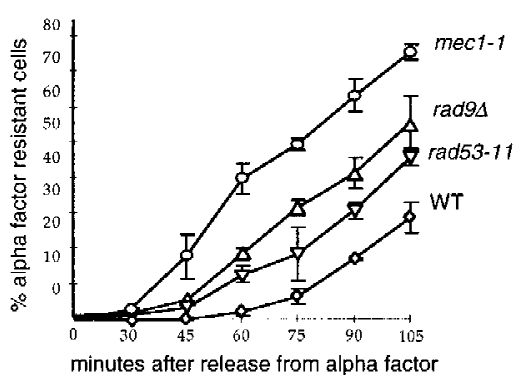

Figure 4. The delay of budding and S-phase entry is shorter in mec1-1, rad53-11, and rad9s strains than in the wild type. (A,B) The isogenic wild type (BY 2006), mec1-1 (BY 2226), rad53-11 (BY 2007), and rad9s (BY2227) strains were arrested by $\alpha$-factor and rel eased into fresh media with or without $0.2 \%$ MMS. The "no M MS" cultures were allowed to progress into the cell cycle. In the "+M MS" cultures, after incubation for $30 \mathrm{~min}$, MMS was inactivated and the cultures were filtered, resuspended in another change of media, and al lowed to grow. (A) Aliquots were taken from treated and untreated cultures to count the percentage of budded cells. $\mathrm{N}$ ote that the 30-min time point for M M S-treated cultures corresponds to the moment of rel ease from M MS. In B, the DNA content for the cells shown in A was determined by FACS and an example of DNA content distribution for the 150-min time point is presented. The 150-min time point for which FACS data are shown is marked by a box in A. (C) The same four strains were arrested by $\alpha$-factor, and $0.2 \%$ M MS was added for the last 30 min before the release from the pheromone. After that, M MS was inactivated and the cultures were filtered into the fresh media. Samples were taken in 15-min intervals and transferred to microtiter plates with $10 \mu \mathrm{g} / \mathrm{ml}$ of $\alpha$-factor, as described in the legend to Fig. 3. Percentage of budded cells was scored after 30 to 45 -min incubation in $\alpha$-factor. Presented are the average values of two independent experiments. 
terestingly, the mec1-1 mutant appears to bud and become $\alpha$-factor resistant more rapidly than the others. In summary, just as was observed for GAL::SWI4-t, in the absence of checkpoint function, the M MS-induced delay of Start is clearly diminished but not completely eliminated.

A RAD53 checkpoint mutant treated with MMS recovers CLN 1 transcription faster than wild type

In the signal transduction cascade from DNA damage to the cell cycle machinery targets, Rad53 is thought to be the most proximal of all the known checkpoint genes to the targets (N avas et al. 1996; Sanchez et al . 1996; Sun et al. 1996). Because mec1-1, rad9s, and rad53-11 mutants exhibit a similarly shortened $\mathrm{G}_{1}$ del ay after M MS treatment, we chose to characterize the rad53-11 mutant in more detail. As expected on the basis of Figure 4A, control and rad53-11 cells express comparable levels of CLN 1 mRNA after release from $\alpha$-factor arrest in the absence of DNA damage (Fig. 5A, B). When these cells are treated with $\mathrm{MMS}$, the initial down-regulation of CLN 1 mRNA is about the same in the rad53-11 and wild-type cells (Fig. 5C,D; data not shown). However, the recovery of high CLN $1 \mathrm{mRN} A$ levels is more rapid in the rad53-11 mutant than in the wild-type cells (Fig. 5C, D).

Because we have shown that CLN mRNA down-regulation and recovery are not dependent on cell cycle progression, we were interested to see whether the same is true for the fast recovery of CLN transcripts in the rad5311 strain. cdc4 rad53-11 double mutants were constructed (see Materials and M ethods), and the cdc4 arrests and M M S treatments were repeated as described for Figure 2. In this case, the results of two experiments with two independent cdc4 rad53-11 isol ates were quantitated and used to produce the plot shown in Figure 6A. It is clear from this analysis that cdc4 rad53-11 strains arrested in $G_{1}$ recover their CLN 1 message levels faster than the cdc4 RAD strain. During the cdc4 arrest, CLN 1 transcript levels are slightly lower in the cdc4 rad53-11 strain as compared with the cdc4 strain (data not shown); so its ability to recover CLN 1 mRN A after MMS treatment cannot be a result of the unusually high CLN1 levels.

Swi 6 mutants treated with MMS also recover CLN 1 transcription faster than wild type

GAL::SWI4-t is capable of reducing the MMS-induced delay of Start, but GAL-induced wild-type Swi4 is not.

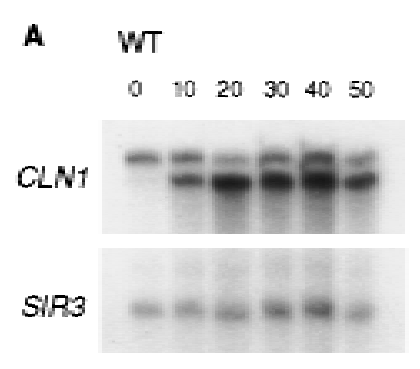

$\operatorname{rad} 53-11$
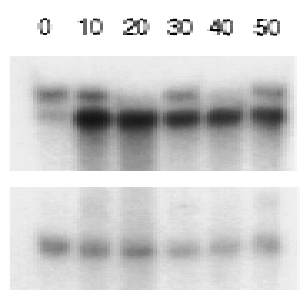

c

WT

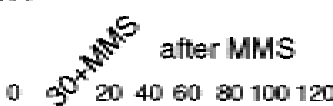

0 $S^{x} 204060 \quad 80100120$

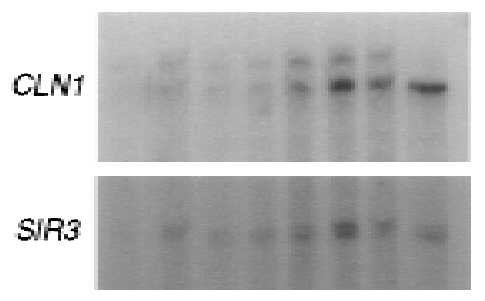

$\operatorname{rad} 53-11$
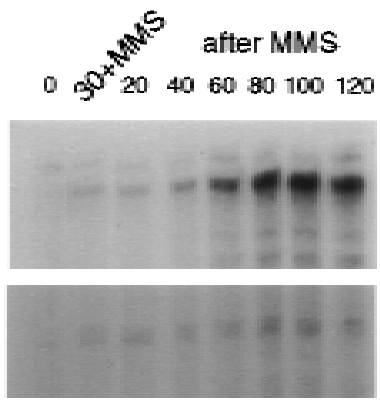

B
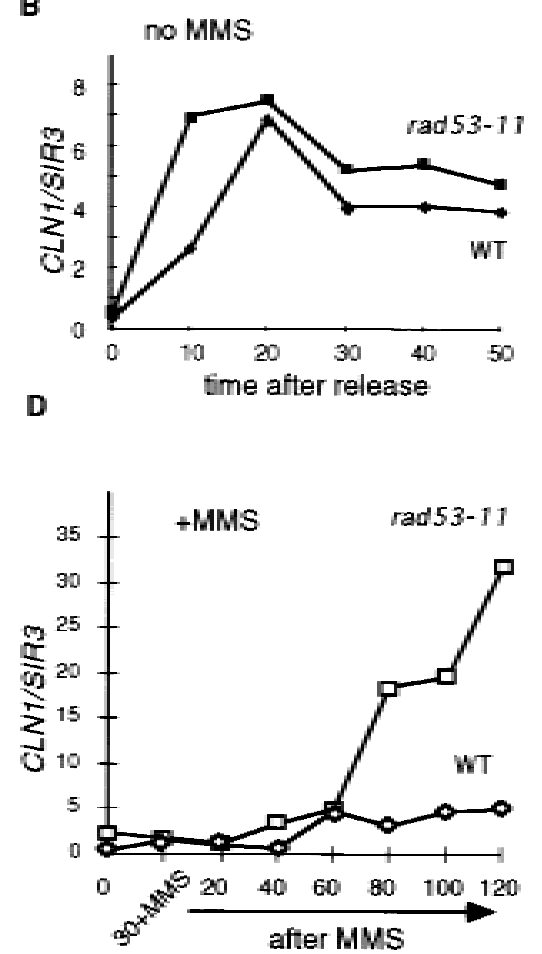

Figure 5. The rad53-11 strain has a faster rate of CLN 1 transcript recovery after M MS than the wild type. (A) The isogenic wild-type (BY 2006) and rad53-11 (BY 2007) strains were arrested by $\alpha$-factor and released as usual. Aliquots were taken in 10-min intervals for $50 \mathrm{~min}, \mathrm{RN}$ As were isolated, and the levels of CLN 1 and SI R3 were measured by S1 protection. (B) Data obtained in A were quantitated as above. (C) The same two strains were treated with M MS in the same way as described in the legend to Fig. 4A. Aliquots were taken before the rel ease from $\alpha$-factor (0), with $0.2 \% \mathrm{MMS}(30+\mathrm{M} M \mathrm{MS})$ and at interval s after M MS was removed. Level s of CLN 1 and SIR3 were measured by S1 protection. (D) The CLN 1 and SIR3 levels shown in C were quantitated, and CLN 1 was normalized to SIR3 and plotted. 
Swi4-t is more stable than wild-type Swi 4, but both proteins are expressed at such high levels under these conditions that this difference is unlikely to be the reason for the selective deregulation of CLN transcripts by Swi4-t. The other important difference between Swi4 and Swi4-t is that Swi4-t has lost the carboxy-terminal domain necessary for association with Swi6 (Sidorova and Breeden 1993). Thus, we wondered whether Swi6 could be the target of negative regulation by the Rad53 pathway under conditions of DNA damage. swi6 mutants grow slowly and do not recover synchronously from $\alpha$-factor arrest; so to avoid these complications, we generated cdc 4 swi $6 \Delta$ and cdc4 SWI 6 strains. These cells were arrested at the $\mathrm{G}_{1} / \mathrm{S}$ transition, and CLN 1 transcript was monitored after cells were treated with a pulse of M M S. As can be seen in Figure 6B, the absence of Swi 6 does not eliminate the drop of CLN1 transcript levels upon MMS treatment, but, like rad53-11, it allows a faster recovery of CLN 1 transcription after MMS (Fig. 6A). Thus, the maintenance of low CLN1 mRN A levels in response to DNA damage is Rad53 dependent and Swi 6 dependent. The requirement for Swi 6 to inhibit CLN expression is surprising because it was first identified as an activator of transcription. However, this result could be explained if Swi6 is modified in response to DN A damage to a form that causes the Swi4/Swi6 complex to repress rather than activate transcription.

Swi 6 undergoes MMS-inducible Rad53-dependent phosphorylation in vivo

Rad53 is a dual-specificity protein kinase whose consensus phosphorylation site is not known (Zheng et al. 1993). U pon treatment with DN A-damaging agents such as hydroxyurea and M MS, Rad53 undergoes phosphorylation, which alters its mobility in SDS-PAGE (Sanchez et al. 1996; Sun et al. 1996). This phosphorylation is performed by an upstream kinase, possibly $M$ ec1, rather than by Rad53 itself (Sanchez et al . 1996; Sun et al . 1996). In vitro Rad53 can phosphorylate itself (Zheng et al. 1993; Fay et al. 1997) and histone Hl (Sun et al. 1996), and Rad53 kinase activity is increased upon treatment with a checkpoint-activating agent, hydroxyurea (Sun et al. 1996). One potential target of Rad53 in living cells is the Dun1 kinase, which is phosphorylated in a Rad53dependent, MMS-inducible manner (Allen et al. 1994). To see whether M M S al so affects the Swi 6 phosphorylation pattern, we monitored Swi6 phosphorylation by peptide mapping using the same M MS treatment conditions we used to follow CLN transcription. Wild-type cells were arrested in $G_{1}$ and released into radioactive orthophosphate-containing media, and MMS was added to one-half of the culture for $40 \mathrm{~min}$. Extracts were made, Swi 6 was immunoprecipitated from these cells, and its phosphorylation state was determined by peptide mapping. Figure 7A shows that upon MMS treatment Swi6 gains phosphates on at least two new peptides (designated $a$ and $b$ ). This phosphorylation can be acquired as early as 20 min after introduction of M M S, and it persists for at least $90 \mathrm{~min}$ after MMS is eliminated (data not
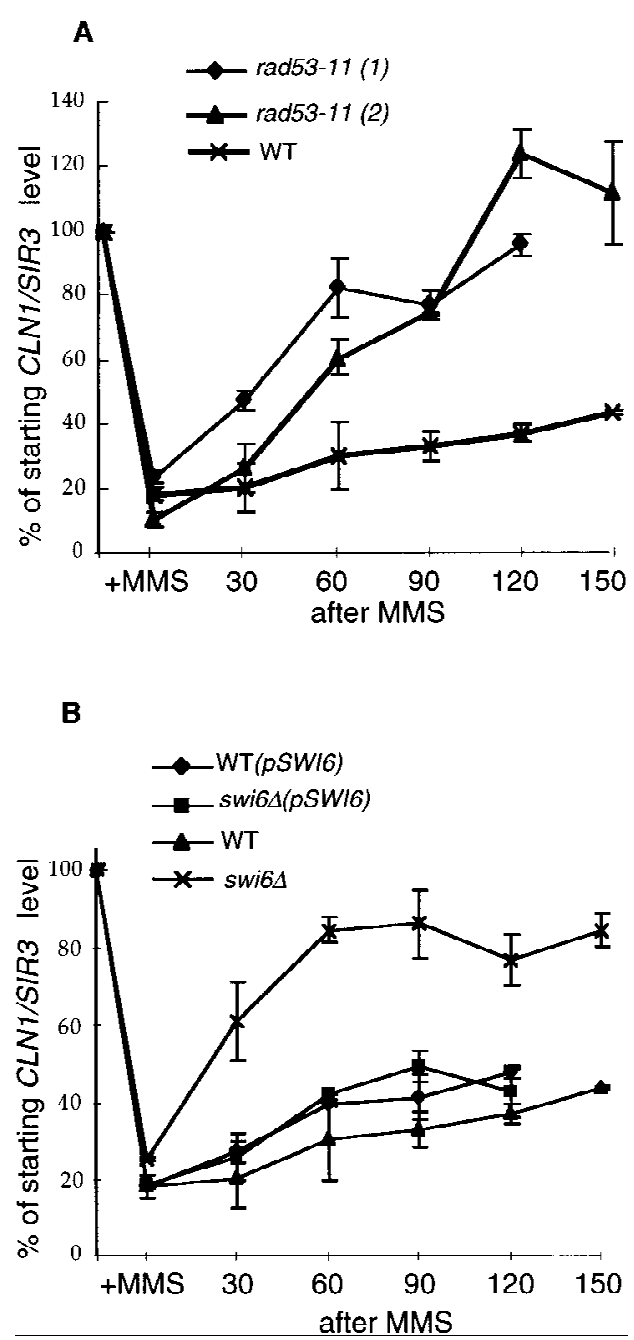

Figure 6. The CLN1 transcription is recovered faster in the cdc4 rad53-11 and cdc4 swi6s strains than in the cdc4 strain upon MMS treatment during the arrest at nonpermissive temperature. The cdc4 (BY2240), two isolates of cdc4 rad53-11 (BY2243 and BY2287) and cdc4 swi6::TRP1 (BY2241) strains, BY2240 transformed with pBD1265 (with SWI6 gene), and BY 2241 transformed with pBD 1265 were treated the same way as described in the legend to Fig. 2. They were first arrested at $37^{\circ} \mathrm{C}$ for $3 \mathrm{hr}$, and then an aliquot from both cultures was collected to serve as control (0), and to the rest of the cultures, $0.1 \%$ MMS was added for $30 \mathrm{~min}$ ( $+\mathrm{MMS}$ ). Then MMS was inactivated and removed by filtration, and the cultures were resuspended in the fresh $37^{\circ} \mathrm{C}$ media and incubated at this temperature for up to $150 \mathrm{~min}$. Aliquots were taken throughout the time of recovery from MMS. RNAs were isolated, and CLN 1 and SIR3 transcript levels were measured. In each case, data from two to three experiments were quantitated and their average plotted. The mRN A levels seen in MMS and after MMS removal are expressed as the percentage of the starting normalized mRNA level seen at $37^{\circ} \mathrm{C}$ in the untreated culture. wt, cdc4 BY2240, wt(pSWI6), cdc4 BY2240 transformed with pSWI6 pBD1265, rad53-11 (1) and rad53-11 (2), cdc4 rad53-11 BY2287 and BY2243, respectively, swi6s, cdc4 swi6::TRP1 BY2241, swi6s(pSWI6) cdc4 swi6::TRP1 BY2241 transformed with pSWI 6 pBD 1265 . 
shown). Thus, these phosphorylations are temporally correlated with the interval during which CLN mRNA levels remain low.

We then asked if this phosphorylation of Swi6 occurs in a checkpoint-defective RAD53 mutant, rad53-11, which is incapable of delaying $G_{1}$ or of prolonging the inhibition of CLN 1 transcription upon MMS treatment. The rad53-11 strain was synchronized and labeled as above, and the Swi 6 phosphorylation pattern was anaIyzed (Fig. 7B). In contrast to the isogenic wild-type cells, there was no MMS-inducible phosphorylation of Swi6 isolated from the MMS-treated rad53-11 strain. Therefore, this phosphorylation of Swi6 requires the checkpoint-proficient Rad53 kinase.

A

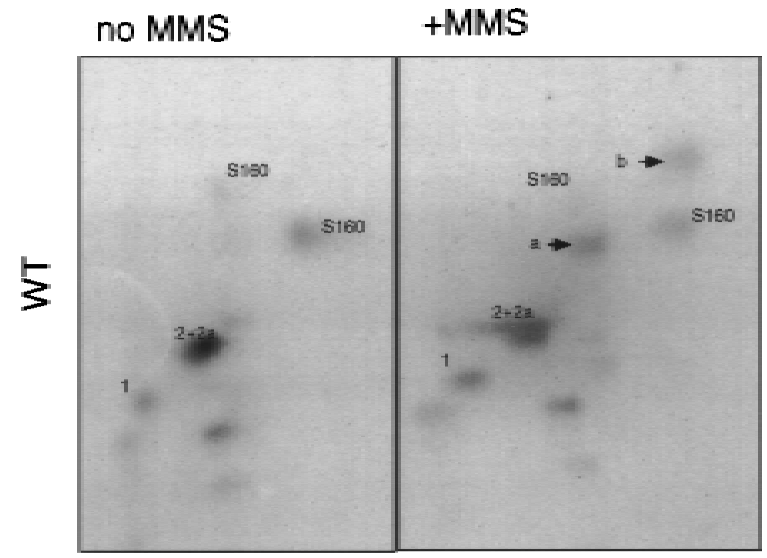

B

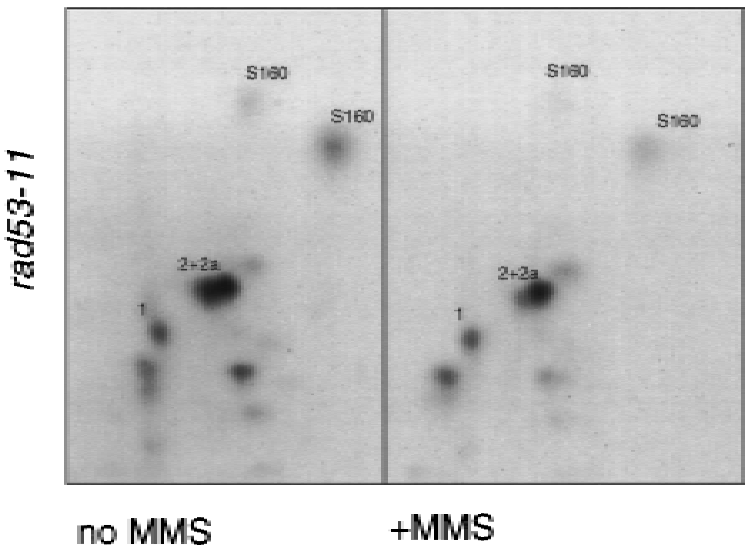

Figure 7. The Swi 6 protein undergoes M M S-inducible RAD53dependent phosphorylation. (A) The wild-type (BY 2006) strain was arrested in $\mathrm{G}_{1}$ by $\alpha$-factor and released into radiolabeled orthophosphate-containing media. MMS $(0.1 \%)$ was added to one-half of this culture for $40 \mathrm{~min}$, after which time both cultures were harvested. Swi 6 was immunoprecipitated out of extracts made from harvested cells, digested with trypsin, and resolved on TLC plates as described in M aterials and M ethods. M M S-inducible peptides $a$ and $b$ are marked by arrows. (B) The rad53-11 (BY 2007) strain was arrested by $\alpha$-factor and released as in $\mathrm{A}, 0.1 \% \mathrm{MMS}$ was added to one-half for $40 \mathrm{~min}$, and then both hal ves were harvested and treated as above. S160 stands for serine-160-containing peptides (Sidorova et al. 1995) that are marked here for the reference. Other major constitutive phosphopeptides of Swi 6 are numbered.

\section{Rad53 or an associated kinase phosphorylates Swi6}

To begin to address whether this phosphorylation of Swi 6 is performed directly by Rad53, we sought to re constitute the MMS-inducible, Rad53-dependent kinase reaction in vitro. First, Rad53 was immunoprecipitated out of untreated and MMS-treated wild-type (WT) or rad53-11 cells, and radioactive ATP was added to monitor phosphorylation. As seen in Figure 8A, the wild-type Rad53 i mmunopreci pitate incorporates phosphate into a single polypeptide of $\sim 90 \mathrm{kD}$ that has been shown previously to be Rad53 itself (Zheng et al. 1993; Sun et al. 1996; Fay et al. 1997). This basal level of Rad53 kinase activity is relatively low but is markedly stimulated by M MS. In contrast, we observe a very low kinase activity in immunoprecipitates of the checkpoint-defective Rad53 isolated from the isogenic rad53-11 strain. Moreover, this low kinase activity cannot be stimulated by MMS (Fig. 8A, lane 4), despite the fact that Rad53-11 undergoes the mobility shift that is correlated with the Mecl-dependent phosphorylation and activation (data not shown). This could indicate that the rad53-11 defect is in its catalytic function, though more complicated scenarios could be proposed. It is of interest because RAD53 is an essential gene (Zheng et al. 1993), and rad53-11 is a viable, checkpoint-deficient allele (Weinert et al. 1994) that has not been characterized in vitro previously. Here, it serves as the ideal negative control, allowing us to conclude that the kinase activity we observe in this assay is Rad53 dependent.

We then performed a Rad53 kinase reaction with exogenously added recombinant Swi6 (Sidorova and Breeden 1993). Because Swi6 and the phosphorylated form of Rad53 migrate very closely in SDS-PAGE, Swi6 was immunopreci pitated from each reaction before electrophoresis (see Materials and Methods for details). As seen with Rad53, we observed highly efficient phosphorylation of Swi6 that was MMS induced and Rad53 dependent (Fig. 8B). The checkpoint-defective Rad53-11, as well as wild-type Rad53 from untreated cells, incorporated about an order of magnitude less phosphate into Swi 6 than the wild-type kinase precipitated from MMStreated cells. Two possibilities could account for this effect. The kinase activity of the Rad53 from undamaged cells could be too low to incorporate substantial radioacti vity into Swi6. Alternatively, M M S could change the specificity of Rad53. We believe that the former possibility is more likely the case, as Rad53 isolated from undamaged cells that overexpresses Rad53 by 10-fold (Zheng et al. 1993; data not shown) is capable of incorporating substantial amounts of phosphate into Swi 6 (Fig. 8C). Thus, the ability to phosphorylate Swi 6 is not restricted to the M M S-activated form of Rad53.

To see whether the pattern of Rad53-dependent phosphorylation of Swi 6 was similar in vivo and in vitro, we used the higher resolution method of peptide mapping. Figure 9, A and B, shows peptide maps of in vivo labeled Swi6, and in this experiment three Rad53-dependent, M M S-inducible phosphopepti des can be readi ly detected (marked a, b, c). Figure 9C shows the peptide map of 
A

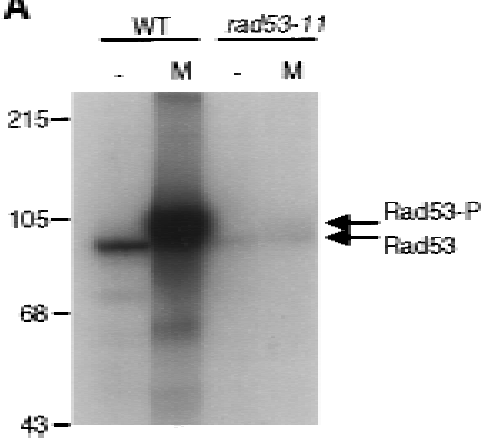

B

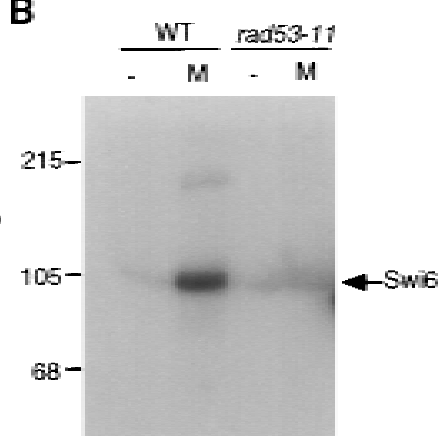

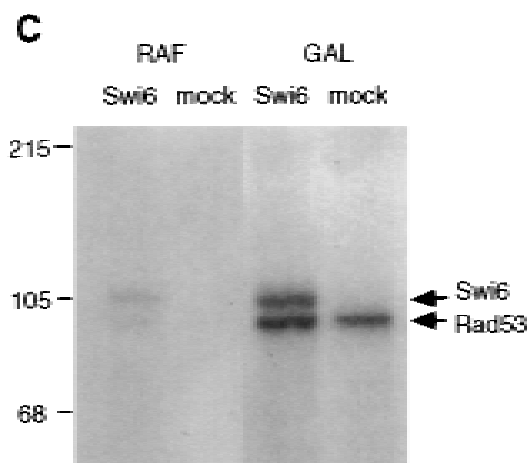

Figure 8. The M M S-inducible, Rad53-dependent phosphorylation of Swi6 can be reconstituted in vitro. (A) Rad53 was immunoprecipitated out of lysates of the wild-type BY 2006 and rad53-11 BY2007 cells that were treated (M) or not treated ( $\rightarrow$ with $0.1 \%$ M MS for $40 \mathrm{~min}$. Radiolabeled ATP was added to immunoprecipitates to allow phosphorylation, and reactions were stopped with SDS loading buffer, boiled, and resolved on SDS-PAGE. The arrows mark the position of Rad53, both the steady-state form (Rad53) and the damage-modified form (Rad53-P), and positions of protein molecular weight markers are shown at left. (B) Rad53 was immunoprecipitated as in A, and recombinant Swi 6 was added al ong with radiolabel ed ATP. Reactions were stopped by addition of AB buffer (see $M$ aterials and M ethods), and Swi 6 was rel eased by incubation at $4^{\circ} \mathrm{C}$ for $30 \mathrm{~min}$ and immunoprecipitated with Swi 6 antibodies. These immunoprecipitates were resolved on SDS-PAGE. Swi6 position is marked by an arrow. (C) Wild-type W303 1A strain transformed with pGAL::RAD53 pBD 2146 was grown either in raffinose (RAF) or gal actose (GAL) to induce overexpression of RAD 53 (see M aterials and M ethods). Protein extracts were prepared out of these cells, Rad53 was immunopreci pitated, and kinase assays with recombinant Swi6 (Swi6) or mock preparation (mock) (see M aterials and M ethods) were performed as described above. Products of kinase reactions were directly loaded onto SDS PAGE. Swi6 and Rad53 positions are marked by arrows.

Swi 6 phosphorylated in vitro by Rad53 that has been immunopreci pitated from the cells overproducing Rad53 from a GAL promoter. Among the products of this reaction are three peptides whose positions of migration are indistinguishable from those of the inducible, Rad53-dependent peptides a, b, and c seen in vivo (Fig. 9B). Figure 9D confirms that these prominent peptides are derived from Swi6, as they are not detectable among the products of the kinase reaction between Rad53 and a mock substrate, which has been prepared from bacteria harboring vector instead of the SWI6-expressing plasmid. In summary, Swi 6 undergoes M M S-induced and Rad53-dependent phosphorylations in vivo, and these phosphorylations appear to be reproducible in vitro with immunoprecipitated Rad53.

\section{Discussion}

MMS-induced $G_{1}$ delay

Previous studies have established that a yeast cell that receives treatment with $U V$ or ionizing irradiation in $G_{1}$

Figure 9. Rad53-dependent phosphopeptides of Swi 6 generated in vivo and in vitro migrate to similar positions on phosphopeptide maps. (A,B) Wild-type (BY 2286) strain was synchronized in $\mathrm{G}_{1}$ by $\alpha$-factor and released into radiolabeled orthophosphate-containing media, and $0.1 \%$ MMS was added to one-half of this culture for 40 min, after which time both halves were harvested. Phosphopeptide maps of Swi6 isolated out of these two cultures were generated as described for Fig. 7 (see M aterials and M ethods for details). M M S-inducible peptides are marked by arrows. Three of such peptides could be detected $(a, b, c)$. Serine 160-containing peptides (S160) are marked for the reference. (C,D) Kinase assays were performed as in Fig. $8 \mathrm{C}$ with Rad53 isolated out of the wild-type strain

A

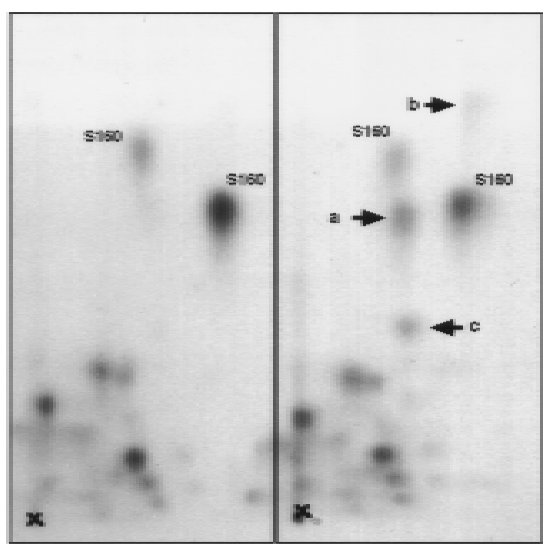

in vivo no MMS
B

in vivo + MMS
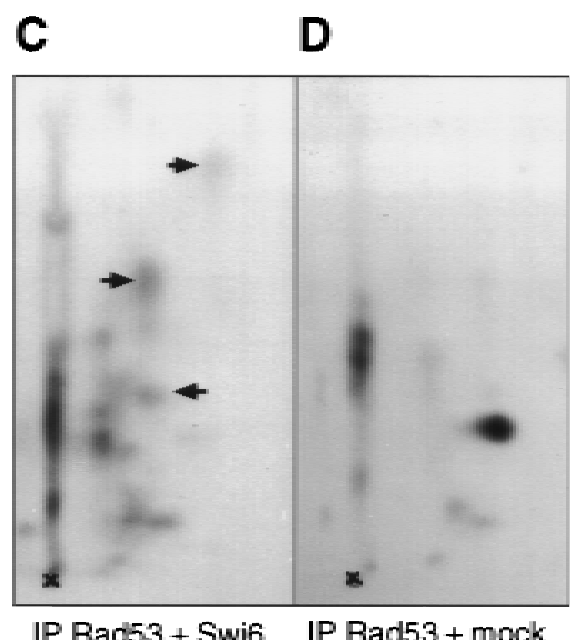

overexpressing RAD 53 from the GAL promoter (BY 2292) with Swi6 (C) or mock preparation (D) as a substrate. Radioactively labeled products were resolved on SDS-PAGE as in Fig. 8C. Swi6 and a corresponding region out of the SDS-PAGE Iane where mock preparation was run were excised, and proteins were eluted and subjected to phosphopeptide analysis as in Figs. 7 and 9 A,B. Rad53dependent in vitro peptides that migrate similar to the M MS-inducible Rad53-dependent peptides generated in vivo are marked by arrows. (x) Map origins. 
can undergo a transi ent and checkpoint-dependent arrest in $G_{1}$ (Si ede et al . 1993, 1994). In this paper we show that a short pulse of MMS, administered either during an $\alpha$ factor-induced $G_{1}$ arrest or immediately after release from the pheromone treatment, can produce a similar effect. With MMS doses of $0.1 \%-0.2 \%$, these cells remain in $G_{1}$ and do not enter $S$ phase for up to $90 \mathrm{~min}$ after withdrawal of the genotoxic agent. The M M S-damaged $G_{1}$ cells show a prolonged sensitivity to $\alpha$-factor that indicates that they pause at or before Start. As with the UV studies, this $G_{1}$ delay is al so dependent on the RAD53, MEC1, and RAD 9 genes (Si ede et al . 1993, 1994, 1996; Weinert et al. 1994). However, in our studies, we have found that these checkpoint mutants only shorten but do not eliminate the delay of Start, suggesting that there may be other contributing factors. In addition, we observe that this $G_{1}$ delay is correlated with a delay in the accumulation of CLN 1 and CLN 2 transcripts.

Recently, Paulovich and Hartwell (1995) showed that continual treatment of $\mathrm{G}_{1}$ cells with low levels of M MS $(0.03 \%)$ induces a profound slowing of S phase, which is dependent on RAD53 and MEC 1 and to a lesser degree, on RAD9, RAD17, and RAD24 (Paulovich et al. 1997a). We have reproduced this finding and observed a dosage dependence to the cell's response. For example, administering $0.05 \% \mathrm{MMS}$ to cells that were released from $\alpha$-factor-induced $\mathrm{G}_{1}$ arrest causes a $<50 \%$ decrease in CLN mRNA levels (data not shown) and no significant $\mathrm{G}_{1}$ delay because these cells will traverse to $\mathrm{S}$ phase almost as fast as untreated controls (J. Sidorova, unpubl.). M MS $(0.1 \%)$ is sufficient to induce $\mathrm{G}_{1}$ del ay if cells are treated during the $\alpha$-factor arrest (Figs. 1 and 3), but $0.2 \%$ M M S is required if it is administered immediately after release (Fig. 4; J. Sidorova, unpubl.). These observations may be explained by the fact that cells continue to grow during an $\alpha$-factor arrest and they attain the critical size required to go through to $S$ phase very rapidly upon release. In this context, a low dose of MMS may not cause enough damage to trigger a response before cells exit $G_{1}$. This is consistent with the possibility that there is a threshold of damage needed to trigger a slowdown in $G_{1}$ or that the del ay can only be triggered at an early step in $\mathrm{G}_{1}$ progression. Alternatively, MMS-induced lesions may be generated too slowly to occur in this time frame or they may be less readily recognized in $G_{1}$ than in $S$ and $\mathrm{G}_{2}$ cells (Paulovich et al. 1997b).

A nother striking feature of the checkpoint-dependent response to $M M S$ damage in $G_{1}$ is that $G_{1}$ cells delay only briefly and then progress into a slow $\mathrm{S}$ phase. This slow $\mathrm{S}$ is most likely owing to incomplete repair of the damage because it is al so checkpoint dependent (Fig. 4; Paulovich and Hartwell 1995). Thus, it appears that the $\mathrm{G}_{1}$ delay is quite transient and not tightl y coupled to the presence of damage. This is in contrast to the $\mathrm{G}_{2}$ arrest, which can last for many hours after a single doublestrand break introduced by $\mathrm{HO}$ endonuclease (Sandell and Zakian 1993). Although the extent of the delay may certainly be affected by the type of DNA damage, one can also hypothesize that a tighter $G_{2}$ arrest has evolved to protect the cell from an irreversible loss of genetic information that would occur during mitosis of unrepaired chromosomes. As such, the $\mathrm{G}_{2}$ checkpoint arrest may be fundamental ly different from the transient delay that occurs in $G_{1}$ cells, despite the fact that the same checkpoint genes are used to detect the damage.

\section{MMS causes the loss of CLN 1 and CLN 2 mRNAs}

In principle, pausing or slowing down during a given phase of the cycle could be achieved by reducing the amount of the cyclin/Cdk kinase that is active during that phase and/or by preventing the switch from one $\mathrm{Cdk}$ form to the other, for example, from $\mathrm{CIn} / \mathrm{Cdk}$ to $\mathrm{Clb} / \mathrm{Cdk}$ in the case of the $\mathrm{G}_{1} / \mathrm{S}$ transition. These effects could be achieved by direct inhibition of kinase activity, depression of cyclin or CDK protein levels, or inhibition of their transcription. In the case of DNA damage-induced delay in $G_{1}$, we have found that CLN 1 and CLN2 message levels are down-regulated by MMS in a dosagedependent manner and are kept low for some time after the damage. Subsequently, the levels of these messages are restored slowly. The loss of CLN transcripts that occurs after brief exposure to $0.1 \%$ M MS cannot be attributed to a global interference with the cell's transcriptional or post-transcriptional activity. Although this nonspecific interference certainly takes place after prolonged incubation with MMS (J. Sidorova, unpubl.), the CLN1 and CLN2 messages are more sensitive to the short exposures and low dose of M MS used in this study than are several other messages. Moreover, CLN 1 sensitivity to MMS can be reduced by overexpression of a truncated form of its transcriptional activator, Swi4-t.

The MM S-induced loss of CLN 1 and CLN 2 messages is reversible, and the rate of recovery of these messages is dependent on Rad53 function. Rad53 slows the recovery of CLN transcript levels both in cycling cells and in $\mathrm{G}_{1^{-}}$ arrested cells. Because this effect is observed in arrested cells, it cannot be an artifact of the differences in the rate of $G_{1}$ progression. Loss of Rad53 function speeds the recovery of CLN transcript levels and reduces the delay of Start. Deregulated expression of CLN1 and CLN2 can also reduce the $G_{1}$ delay in response to DNA damage. Thus, the simplest interpretation of these findings is that Rad53-dependent inhibition of CLN transcription contributes to the delay of Start in MMS-treated cells. Rad53 is known to play a role in transcriptional activati on of genes requi red for DN A repair (A boussekhra et al. 1996; Kiser and Weinert 1996; N avas et al. 1996), and our data indicate that this kinase may have an additional role in repressing transcription of genes that promote progression through the cell cycle.

The role of Swi4 and Swi 6 in MMS-induced down-regulation of CLN s

The Swi4/Swi6 complex induces $G_{1}$ /S-specific transcription of CLN 1 and CLN2. Swi 4 is the DNA-binding subunit of the complex, and in the absence of Swi4, CLN transcription is greatly reduced ( $\mathrm{N}$ asmyth and Dirick 1991; Ogas et al. 1991; Cross et al. 1994; Stuart and Wit- 
tenberg 1994; Partridge et al . 1997). Lack of Swi 6 leads to a constitutive intermediate level of CLN transcription (Dirick et al. 1992; Lowndes et al. 1992). These data have led to the view that Swi 4 is the primary activator of CLN transcription and Swi 6 plays a regulatory role, both enhancing and repressing CLN transcription depending on the phase of the cell cycle. It is therefore possible that Swi 6 may also regulate the activity of the Swi4/Swi6 complex in response to DNA damage. Swi 6 could be modified by a DNA damage-dependent mechanism and shift from an activating to a repressing component of the Swi 4/Swi 6 complex. This would repress CLN transcription and delay the $G_{1} / S$ transition. In agreement with this idea, the absence of Swi6, but not Swi4, causes cells to lose viability rapidly in the presence of MMS (Johnston and Johnson 1995). In addition, we find that the lack of Swi6 can actually increase the rate of CLN 1 transcript recovery after $M M S$, similar to the effect observed in cells with defective Rad53 (Fig. 6). Finally, we have observed that Swi 6 undergoes an MMS-dependent change in phosphorylation in wild-type but not rad53-11 cells. In vivo, we observe two to three new phosphorylations on Swi6, which are induced by MMS treatment, and these phosphorylations are present throughout the period when CLN transcription is low. In vitro Rad53, obtained from MMS-treated wild-type yeast cells or from cells overexpressing this kinase from the GAL promoter, can phosphorylate exogenous Swi6, and three phosphopeptides, which appear to comigrate with the MM S-inducible in vivo phosphopeptides, are observed. The rad53-11 strain is unable to promote MMS-inducible phosphorylation of Swi 6 in vivo or in vitro. This mutant kinase has a dramatically reduced activity as judged by its decreased ability to phosphorylate itself, and it does not support phosphorylation of the exogenous Swi6. Taken together, all these observations strongly indicate that Swi6 is either a direct substrate of a damage-activated Rad53 in living cells or it is phosphorylated by a Rad53-activated kinase that is associated with Rad53.

These results give rise to the following model for the checkpoint induced by DNA damage (Fig. 10). When $\mathrm{G}_{1}$ cells are subjected to DN A damage by MMS, there is an immediate drop in CLN1 and CLN 2 messages that is Rad53-independent. This drop could be mediated by specific promoter elements or by alterations in mRN A stability, and this would be expected to rapidly reduce the rate of $G_{1}$ progression. This delay is extended by a Rad53- and Swi6-dependent inhibition of further CLN transcription. Temporally correlated with this inhibition, there is a Rad53-dependent change in the phosphorylation state of Swi6, which we speculate may inhibit Swi6 function and provide the mechanism for repressing CLN transcription.

The inhibition of CLN expression that we observe in response to MMS may not be universal for every kind of damage but is likely to be one of the mechanisms that delay Start in response to DNA damage. Moreover, the recent finding that ectopic overproduction of CLN 1 can increase genomic instability in wild-type cells and leads to even more instability and cell death in checkpoint-

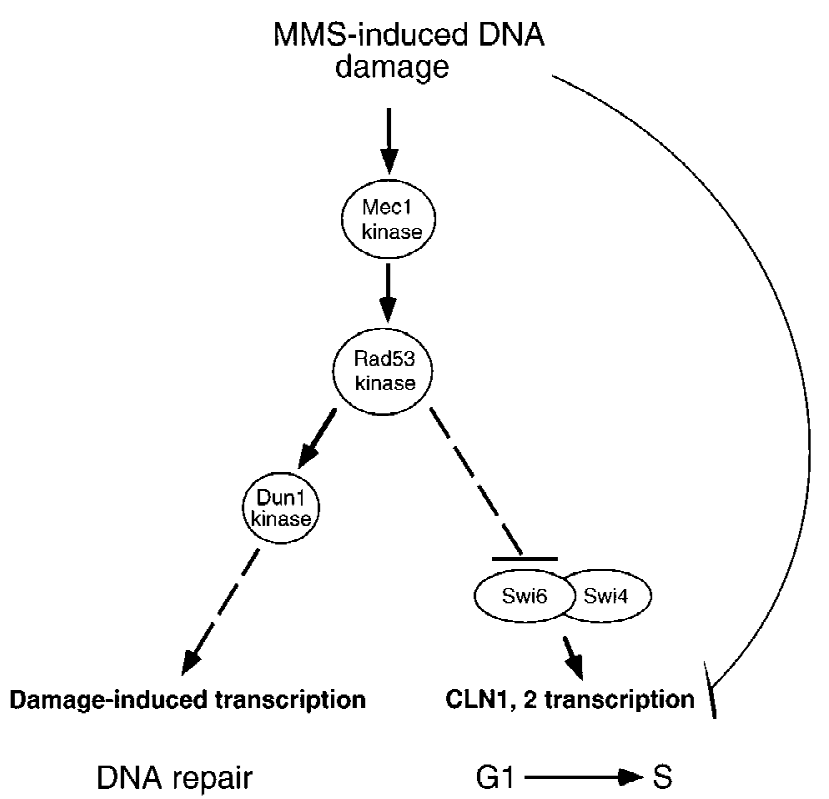

Figure 10. A model for the MMS-induced changes in transcription. As observed previously, M MS-induced DN A damage activates transcription of many genes involved in DNA repair and replication. In addition, it inhibits transcription of the $\mathrm{G}_{1} / \mathrm{S}$ specific cyclins CLN 1 and CLN2. M MS causes a rapid and prolonged repression of CLN 1 and CLN 2 transcription, owing to at least two pathways of regulation. The immediate drop in CLN 1 and CLN 2 transcription is Rad53 and Swi6 independent. Subsequent maintenance of this low level requires Rad53 and may involve Rad53-mediated inactivation of the Swi4/Swi6 complex by phosphorylation of Swi6. In this way, Rad53 plays a central role in both inducing repair of DNA damage and in delaying entry into S phase.

deficient mec1-1 cells (Vallen and Cross 1995) suggests that the tight control over CLN levels may be crucial not only for cells with damaged DNA but also for undamaged cells. At the same time it is clear that the loss of CLN transcripts is certainly not the only mechanism involved in delaying Start, because ectopic expression of CLNs does not eliminate the delay completely. It is ultimately possible that there are several levels of regulation within $\mathrm{G}_{1}$, both cyclin-mediated and independent, that help to protect cells from DNA damage.

\section{Materials and methods}

Strains and plasmids

The yeast strains used in this study are listed in Table 1 . The plasmid pBD 1168 is a Y Cp50 vector with GAL::SWI4-t and was described previously (Sidorova and Breeden 1993). The pBD860 is YCp50 with no insert. The plasmid pBD1265 has been described previously (Sidorova and Breeden 1993) and is a $2 \mu$ vector with the SWI 6 gene. The plasmid pBD2146 is a kind gift of David Stern and has been described by Zheng et al. (1993) as pN B187-SPK1.

Growth conditions

All rich (YEP) and minimal (YC) media and growth conditions were as described before (Breeden and Mikesell 1991). Cultures 
Table 1. Strains used in this study

\begin{tabular}{|c|c|c|}
\hline Strain & Genotype & Source \\
\hline W303-1a & MATa ade2 his3 leu2-3,112 trp1-1 ura3 & Sidorova and Breeden (1993) \\
\hline BY 600 & MATa swi6::TRP1 ade2 ho::IacZ ura3 his3 leu2-3,112 trp1-1 can1-100 met2 & Sidorova and Breeden (1993) \\
\hline BY 665 & MAT $\alpha$ cdc4-1 adel ade2 leu2 lys2 ural & L. Hartwell (FHCRC, Seattle, WA) \\
\hline BY 1365 & MATa cdc28-13 ade2 ade3 leu2 trp1-1 ura3 & J. Roberts (FHCRC, Seattle, WA) \\
\hline BY 1699 & MAT $\alpha$ cdc28-13 ade2 ura3 trp1 leu2 ho::IacZ & BY $1365 \times$ BY 600 \\
\hline BY 1956 & $\begin{array}{l}\text { MATa swi6::TRP1 swi6-38::LEU } 2 \text { ade2 ho::IacZ ura3 his3 leu2-3,112 trp1-1 } \\
\text { can1-100 met2 }\end{array}$ & Breeden collection \\
\hline BY 2006 & MATa ura3 leu2 trp1 his3 & Paulovich and Hartwell (1995) \\
\hline BY 2007 & MATa ura3 leu2 trp1 his3 rad53-11::U RA3 & Paulovich and Hartwell (1995) \\
\hline BY 2181 & MAT $\alpha$ cdc4-1 leu2 rad53-11::U RA3 & BY $665 \times$ BY 2007 \\
\hline BY 2226 & MATa ura3 Ieu2 trp1 his3 mec1-1::HIS3 & Paulovich and Hartwell (1995) \\
\hline BY 2227 & MATa ura3 leu 2 trp1 his3 rad9s::LEU 2 & Paulovich et al. (1997a) \\
\hline BY 2235 & MATa ura3 leu2-3,112 trp1 his3 & Breeden collection \\
\hline BY 2240 & MAT $\alpha$ cdc4-1 leu2 & BY 1956 ×BY 2181 \\
\hline BY 2241 & MAT $\alpha$ cdc4-1 leu2 trp1 swi6::TRP1 & BY $1956 \times$ BY 2181 \\
\hline BY 2243 & MAT $\alpha$ cdc4-1 leu2 rad53-11::U RA3 & BY 1956 ×BY 2181 \\
\hline BY 2286 & MATa ura3 leu2-3,112 trp1 his3 & Breeden collection \\
\hline BY 2287 & MAT $\alpha$ cdc4-1 leu2 trp1 rad53-11::U RA3 & BY 1956 ×BY 2181 \\
\hline BY 2292 & MATa leu2-3,112 ura3-52 (pN B187-SPK1) & Zheng et al. (1993) \\
\hline
\end{tabular}

used for labeling with ${ }^{32} \mathrm{PO}_{4}$ were allowed to double at least once in low phosphate YEP media with $2 \%$ glucose (Rubin 1975) before the experiment. For synchrony experiments, cultures were grown to an $\mathrm{OD}_{660}$ of 0.2 and arrested by addition of $\alpha$-factor or by shifting to high temperature. Arrest with $\alpha$-factor was performed with $5 \mathrm{mg} / \mathrm{liter}$ of this pheromone in low phosphate or YEP media with appropriate carbon source typically for 90-120 min. Cells were released from the arrest by filtration. cdc strains were arrested at $37^{\circ} \mathrm{C}$ for $3 \mathrm{hr}$. M M S was added from a $100 \%$ or a $10 \%$ solution directly to the cultures and the cultures were shaken vigorously to ensure resuspension of MMS and incubated for times indicated in the figure legends (typically $30 \mathrm{~min}$ ). As a rule, immediately before washing away by filtration, MMS was inactivated by the addition of an equal volume of freshly made $10 \%$ sodium thiosul fate solution to the culture. Thiosulfate addition does not affect the del ay of S phase or CLN levels (J. Sidorova, unpubl.). In experiments involving induction of the GAL promoter, cultures were grown in selective media with $2 \%$ raffinose for $12-20 \mathrm{hr}$, switched to the rich media with raffinose, and synchronized by $\alpha$-factor. Galactose was added 30-60 min before the release from $\alpha$-factor. GAL induction of RAD53 expression was performed in sel ective media for 3-4 hr.

\section{RNA isolation and S1 protection}

These procedures were performed as described previously (Breeden and Mikesell 1991), except for the annealing of radiolabeled probes to RNAs, which was done in formamide buffer (80\% formamide, $40 \mathrm{~mm}$ PIPES at $\mathrm{pH} 6.4,400 \mathrm{~mm} \mathrm{~N} \mathrm{aCl}, 1 \mathrm{~mm}$ EDTA at pH 8.0) at $30^{\circ} \mathrm{C}$. The probes used for detection of CLN 1 and CLN2, CLN3, CDC6, MATal, HIS3, and SIR3 transcripts are described (Breeden and Mikesell 1991; Foster et al. 1993; Mclnerny et al. 1997). mRNA levels were measured with a Phosphorlmager 400A (M olecular Dynamics, Sunnyvale, CA), and the signals were quantitated using ImageQuant software.

\section{FACS analysis}

For FACS analysis of DNA content, cells were fixed in $70 \%$ ethanol for at least $1 \mathrm{hr}$, washed twice in $50 \mathrm{~mm}$ Tris- $\mathrm{HCl}(\mathrm{pH}$
7.8), resuspended in the same buffer, and digested with RN ase $(20 \mu \mathrm{g} / \mathrm{ml})$ for $4 \mathrm{hr}$ at $37^{\circ} \mathrm{C}$. Cells were pelleted and resuspended in $125 \mathrm{~mm}$ Tris- $\mathrm{HCl}$ (pH 7.8), $105 \mathrm{~mm} \mathrm{NaCl}, 39 \mathrm{~mm} \mathrm{M} \mathrm{gCl}$, and $20 \mu \mathrm{g} / \mathrm{ml}$ of propidium iodide. Cells were analyzed on Becton Dickinson FACScan, and the obtained information was presented using CellQuest software.

\section{Protein analysis}

The ${ }^{32} \mathrm{PO}_{4}$ labeling conditions, extract preparation, Swi 6 immunoprecipitation, and phosphopeptide mapping procedures were performed exactly as described (Sidorova et al. 1995). Immunoprecipitation of Rad53 for kinase assays was performed as described (Zheng et al. 1993; Sun et al. 1996) with previously characterized polyclonal antibodies, which were kindly provided by David Stern and Steve Elledge (Zheng et al. 1993; Allen et al. 1994), with the following modifications: The extract preparation and immunoprecipitation buffer $[20 \mathrm{~mm}$ Tris- $\mathrm{HCl}$ (pH 8.0), $10 \mathrm{~mm} \mathrm{MgCl}_{2}, 1 \mathrm{~mm}$ EDTA, $5 \%$ glycerol, $0.3 \mathrm{~m}$ $\left(\mathrm{NH}_{4}\right)_{2} \mathrm{SO}_{4}, 1 \mathrm{~mm}$ DTT, $1 \mathrm{~mm}$ PMSF, $1 \mathrm{~mm}$ benzamidine, 1 $\mu \mathrm{g} / \mathrm{ml}$ of leupeptin, $1 \mu \mathrm{g} / \mathrm{ml}$ of pepstatin A, $1 \mu \mathrm{g} / \mathrm{ml}$ of sodium orthovanadate] was supplemented with $0.1 \%$ N P-40. Immunoprecipitates were washed three times with the original washing buffer (PBS, 1\% Triton X-100, 10\% glycerol, $100 \mu \mathrm{m}$ sodium orthovanadate), three times with washing buffer with $0.8 \mathrm{~m}$ $\mathrm{N} \mathrm{aCl}$, and once with the same buffer with $1.6 \mathrm{M} \mathrm{N} \mathrm{aCl}$. Rad53 kinase reaction was performed as described (Zheng et al. 1993; Sun et al. 1996). Recombinant Swi6 (100-200 ng) (Sidorova and Breeden 1993) was used per reaction. In some cases Swi6 was substituted with the mock preparation, which is a protein extract fraction obtained using Swi6 purification protocol from Escherichia coli harboring an empty vector instead of the Swi6expressing plasmid. Products of the kinase reaction were either loaded directly onto SDS-PAGE or Swi 6 was reprecipitated out of reaction mixture. In the latter case, 24 volumes of AB buffer (20 mM Tris- $\mathrm{HCl}$ at pH 7.5, $50 \mathrm{~mm} \mathrm{NaCl}, 0.5 \% \mathrm{NP}-40,0.5 \%$ DOC, $0.3 \%$ SDS) were added to the reactions and Swi 6 was eluted for $30 \mathrm{~min}$ at $4^{\circ} \mathrm{C}$. This step was necessitated by the fact that after a kinase reaction, Swi 6 is found predominantly associated with beads. After elution was performed as described, 
Rad53 remained associated with agarose beads, whereas Swi6 was released (data not shown). These eluates were then separated from the protein-A agarose beads (GIBCO BRL) and incubated with anti-Swi6 polyclonal antibodies (Sidorova and Breeden 1993) and a fresh portion of protein A-agarose beads (Sidorova and Breeden 1993). Precipitates were washed with RIPA and high salt buffers (10 mm Tris- $\mathrm{HCl}$ at pH 7.5, $2 \mathrm{M} \mathrm{N} \mathrm{aCl}$, $1 \%$ N P-40, 0.5\% DOC) and resolved on SDS-PAGE.

\section{Acknowledgments}

We gratefully acknowledge members of the laboratory for support and helpful discussions. Special thanks are also due to David Stern for a gift of the GAL::SPK1 strain and for the Rad53 antibodies, to Steve Elledge for Rad53 antibodies, and to Lee Hartwell and members of his laboratory for providing the strains and for hel pful critiques. This research was funded by a grant (GM 41073) from the $\mathrm{N}$ ational Institutes of Health to L.L.B.

The publication costs of this article were defrayed in part by payment of page charges. This article must therefore be hereby marked "advertisement" in accordance with 18 USC section 1734 solely to indicate this fact.

\section{References}

A boussekhra, A. , J.E. Vialard, D.E. M orrison, M. Angeles de la Torre-Ruiz, L. Cernakova, F. Fabre, and N .F. Lowndes. 1996. A novel role for the budding yeast RAD 9 checkpoint gene in DNA damage-dependent transcription. EMBO J. 15: 39123922.

Al-Khodairy, F. and A.M. Carr. 1992. DNA repair mutants defining $\mathrm{G}_{2}$ checkpoint pathways in Schizosaccharomyces pombe. EMBO J. 11: 1343-1350.

Allen, J.B., Z. Zhou, W. Siede, E.C. Friedberg, and S.J. Elledge. 1994. The SAD1/RAD53 protein kinase controls multiple checkpoints and DNA damage-induced transcription in yeast. Genes \& Dev. 8: 2401-2415.

Baroni, M.D., P. M onti, and L. Alberghina. 1994. Repression of growth-regulated G1 cyclin expression by cyclic AMP in budding yeast. Nature 371: 339-342.

Breeden, L. 1996. Start-specific transcription in yeast. In Current topics in microbiology and immunology (ed. P.J. Farnham), pp. 95-127. Springer-Verlag, Berlin, Germany.

Breeden, L. and G. Mikesell. 1991. Cell cycle-specific expression of the SWI4 transcription factor is required for the cell cycle regulation of HO transcription. Genes \& Dev. 5: 1183-1190.

Cross, F.R. 1995. Starting the cell cycle: What's the point? Curr. Opin. Cell Biol. 7: 790-797.

Cross, F.R., M. Hoek, J.D. McKinney, and A.H. Tinkel enberg. 1994. Role of Swi4 in cell cycle regulation of CLN2 expression. Mol. Cell. Biol. 14: 4779-4787.

Dhillon, N. and M.F. Hoekstra. 1994. Characterization of two protein kinases from Schizosaccharomyces pombe involved in regulation of DNA repair. EMBO J. 13: 2777-2788.

Dirick, L., T. Moll, H. Auer, and K. N asmyth. 1992. A central role for SWI 6 in modulating cell cycle Start-specific transcription in yeast. Nature 357: 508-513.

Elledge, S.J. and R.W. Davis. 1989. Identification of the DNA Damage-Responsive Element of RNR2 and evidence that four distinct cellular factors bind it. Mol. Cell. Biol. 9: 53735386.

Fay, D.S., Z. Sun, and D.F. Stern. 1997. Mutations in SPK1/ RAD 53 that specifically abolish checkpoint but not growthrelated functions. Curr. Genet. 31: 97-105.
Foster, R., G.E. Mikesell, and L. Breeden. 1993. Multiple Swi6dependent cis-acting elements control SWI4 transcription through the cell cycle. Mol. Cell. Biol. 13: 3792-3801.

Hari, K.L., A. Santerre, J.J. Sekel sky, K.S. M cKim, J.B. Boyd, and R.S. Hawley. 1995. The mei-41 gene of D. melanogaster is a structural and functional homolog of the human A taxia Telangiectasia gene. Cell 82: 815-821.

Hunter, T. 1995. When is a li pid kinase not a lipid kinase? When it is a protein kinase. Cell 83: 1-4.

Johnston, L.H. and A.L. Johnson. 1995. The DN A repair genes RAD54 and U NG1 are cell cycle regulated in budding yeast but MCB promoter elements have no essential role in the DN A damage response. Nucleic Acids Res. 23: 2147-2152.

King, R.W., R.J. Deshaies, J.-M. Peters, and M.W. Kirschner. 1996. How proteolysis drives the cell cycle. Science 274: 1652-1659.

Kiser, G.L. and T.A. Weinert. 1996. Distinct roles of yeast MEC and RAD checkpoint genes in transcriptional induction after DN A damage and implications for induction. Mol. Biol. Cell 7: 703-718.

Lowndes, N.F., A.L. Johnson, L. Breeden, and L.H. Johnston. 1992. SWI6 protein is required for transcription of the periodically expressed DNA synthesis genes in budding yeast. Nature 357: 505-508.

Lydall, D. and T. Weinert. 1995. Yeast checkpoint genes in DN A damage processing: Implications for repair and arrest. Science 270: 1488-1491.

McClanahan, T. and K. M cEntee. 1984. Specific transcripts are elevated in Saccharomyces cerevisiae in response to DNA damage. Mol. Cell. Biol. 4: 2356-2363.

M clnerny, C.J., J.F. Partridge, G.E. Mikesell, D.P. Creemer, and L.L. Breeden. 1997. A novel M cm1-dependent promoter element in the SWI4, CLN3, CDC6, and CDC47 promoters activates $M / G_{1}$-specific transcription. Genes \& Dev. 11: $1277-1288$.

Morrow, D.M., D.A. Tagle, Y. Shiloh, F.S. Collins, and P. Hieter. 1995. TEL1, an S. cerevisiae homolog of the human gene mutated in ataxia telangiectasia, is functionally related to the yeast checkpoint gene MEC1. Cell 82: 831-840.

$\mathrm{N}$ asmyth, K. 1996. At the heart of the budding yeast cell cycle. Trends Genet. 12: 405-412.

N asmyth, K. and L. Dirick. 1991. The role of SWI4 and SWI6 in the activity of G1 cyclins in yeast. Cell 66: 995-1013.

N avas, T.A., Y. Sanchez, and S.J. Elledge. 1996. RAD 9 and DN A polymerase $\epsilon$ form parallel sensory branches for transducing the DNA damage checkpoint signal in Saccharomyces cerevisiae. Genes \& Dev. 10: 2632-2643.

Ogas, J., B.J. Andrews, and I. Herskowitz. 1991. Transcriptional activation of CLN1, CLN2, and a putative new G1 cyclin (HCS26) by SWI4, a positive regulator of G1-specific transcription. Cell 66: 1015-1026.

Partridge, J.F., G.E. Mikesell, and L.L. Breeden. 1997. Cell cycledependent transcription of CLN1 involves Swi4 binding to MCB-like elements. J. Biol. Chem. 272: 9071-9077.

Paulovich, A.G. and L.H. Hartwell. 1995. A checkpoint regulates the rate of progression through S Phase in S. cerevisiae in response to DNA damage. Cell 82: 841-847.

Paulovich, A.G., R.U. Margulies, B.M. Garvik, and L.H. Hartwell. 1997a. RAD9, RAD17, and RAD 24 are required for $S$ phase regulation in Saccharomyces cerevisiae in response to DN A damage. Genetics 145: 45-62.

Paulovich, A.G., C.P. Toczyski, and L.H. Hartwell. 1997b. When checkpoints fail. Cell 88: 315-321.

Pecker, I., K.B. Avraham, D.J. Gilbert, K. Savitsky, G. Rotman, R. Hamic, T. Fukso, E. Schrock, S. Hirotsune, D. Tagle, F.S. Collins, A. Wynshaw-Boris, T. Ried, N.G. Copeland, N.A. 
Jenkins, Y. Shiloh, and Y. Ziv. 1996. Identification and chromosomal localization of ATM, the murine homolog of the ataxia-telangiectasia gene. Genomics 35: 39-45.

Rubin, G.M. 1975. Preparation of RNA and ribosomes from yeast. Methods Cell Biol. 12: 45-64.

Ruby, S.W. and J.W. Szostak. 1985. Specific Saccharomyces cerevisiae genes are expressed in response to DNA-damaging agents. Mol. Cell. Biol. 5: 75-84.

Sanchez, Y., B.A. Desany, W.J. Jones, Q. Liu, B. Wang, and S.J. Elledge. 1996. Regulation of RAD53 by the ATM-like kinases MEC 1 and TEL 1 in yeast cell cycle checkpoint pathways. Science 271: 357-360.

Sandell, L.L. and V.A. Zakian. 1993. Loss of a yeast telomere: Arrest, recovery and chromosome loss. Cell 75: 729-739.

Savitsky, K., A. Bar-Shira, S. Gilad, G. Rotman, Y. Ziv, L. Vanagaite, D.A. Tagle, S. Smith, T. Uziel, and S. Sfez. 1995. A single ataxia telangiectasia gene with a product similar to PI-3 kinase. Science 268: 1700-1701.

Sidorova, J. and L. Breeden. 1993. Analysis of the SWI4/SWI6 protein complex, which directs $\mathrm{G}_{1} / \mathrm{S}$-specific transcription in Saccharomyces cerevisiae. Mol. Cell. Biol. 13: 1069-1077.

Sidorova, J., G. Mikesell, and L. Breeden. 1995. Cell cycle regulated phosphorylation of Swi 6 controls its nuclear localization. Mol. Biol. Cell 6: 1641-1658.

Siede, W., A.S. Friedberg, and E.C. Friedberg. 1993. RAD9-dependent $\mathrm{G}_{1}$ arrest defines a second checkpoint for damaged DNA in the cell cycle of Saccharomyces cerevisiae. Proc. Natl. Acad. Sci. 90: 7985-7989.

Siede, W., A.S. Friedberg, I. Dianova, and E.C. Friedberg. 1994. Characterization of $\mathrm{G}_{1}$ checkpoint control in the yeast Saccharomyces cerevisiae following exposure to DNA-damaging agents. Genetics 138: 271-281.

Siede, W., J.B. Allen, S.J. Elledge, and E.C. Friedberg. 1996. The Saccharomyces cerevisiae M EC 1 gene, which encodes a homolog of the human ATM gene product, is required for $\mathrm{Gl}$ arrest following radiation treatment. J. Bacteriol. 178: 58415843.

Stuart, D. and C. Wittenberg. 1994. Cell cycle-dependent transcription of CLN 2 is conferred by multiple distinct cis-acting regulatory elements. Mol. Cell. Biol. 14: 4788-4801.

Sun, Z., D.S. Fay, F. Marini, M. Foiani, and D.F. Stern. 1996. Spk1/Rad53 is regulated by Mecl-dependent protein phosphorylation in DNA replication and damage checkpoint pathways. Genes \& Dev. 10: 395-406.

Tokiwa, G., M. Tyers, T. Volpe, and B. Futcher. 1994. Inhibition of $\mathrm{G} 1$ cyclin activity by the Ras/cAMP pathway in yeast. Nature 371: 342-345.

Vallen, E.A. and F.R. Cross. 1995. Mutations in RAD27 define a potential link between $G_{1}$ cyclins and DNA replication. Mol. Cell. Biol. 15: 4291-4302.

Weinert, T. and L. Hartwell. 1989. Control of G2 by the RAD9 gene of Saccharomyces cerevisiae. J. Cell Sci. (Suppl.) 12: $145-148$.

Weinert, T., G.L. Kiser, and L.H. Hartwell. 1994. Mitotic checkpoint genes in budding yeast and the dependence of mitosis on DNA replication and repair. Genes \& Dev. 8: 652-665.

Willems, A.R., S. Lanker, E.E. Patton, K.L. Craig, T.F. N ason, N. M athias, R. Kobayashi, C. Wittenberg, and M. Tyers. 1996. Cdc53 targets phosphorylated $\mathrm{G} 1$ cyclins for degradation by the ubiquitin proteolytic pathway. Cell 86: 453-463.

Zheng, P., D.S. Fay, J. Burton, H. Xiao, J.L. Pinkham, and D.F. Stern. 1993. SPK1 is an essential S-phase specific gene of Saccharomyces cerevisiae that encodes a nuclear serine/ threonine/tyrosine kinase. Mol. Cell. Biol. 13: 5829-5842. 


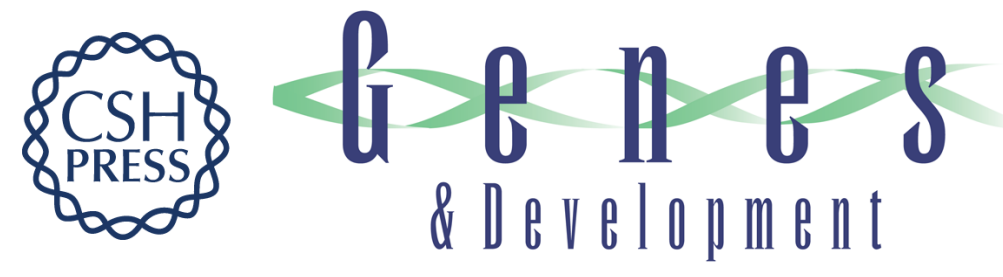

\section{Rad53-dependent phosphorylation of Swi6 and down-regulation of CLN1 and CLN2 transcription occur in response to DNA damage in Saccharomyces cerevisiae}

Julia M. Sidorova and Linda L. Breeden

Genes Dev. 1997, 11:

Access the most recent version at doi:10.1101/gad.11.22.3032

References This article cites 48 articles, 26 of which can be accessed free at:

http://genesdev.cshlp.org/content/11/22/3032.full.html\#ref-list-1

License

Email Alerting Receive free email alerts when new articles cite this article - sign up in the box at the top Service right corner of the article or click here.

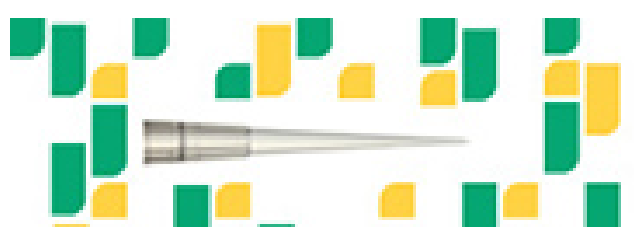

Focused on your science. 